\title{
SCIDiC
}

International Journal of Anatomy and Applied Physiology (IJAAP)

ISSN: 2572-7451

\section{Study On Effect Of Exercise On Blood Pressure, Heart Rate, Respiratory Rate And Physiological Blood Parameters}

Research Article

GN Shashi Rekha ${ }^{1 *}$, Supriya Garapati ${ }^{2}$, Asra Anjum ${ }^{3}$

${ }^{1}$ Associate Professor, Department of Physiology, Mamata Academy of Medical Sciences, Bachupally, Hyderabad, Telangana State, India.

${ }^{2}$ Professor and HOD, Department of Anatomy, Mamata Academy of Medical Sciences, Bachupally, Hyderabad, Telangana State, India.

${ }^{3}$ Tutor, Department of Anatomy, Mamata Academy of Medical Sciences, Bachupally, Hyderabad, Telangana State, India.

\section{Abstract}

Background: One of the most common medical disorders is hypertension which is associated with an increased incidence of all-cause and cardiovascular disease mortality. Exercise programs that primarily involve endurance activity prevent the development of hypertension and lower blood pressure in adults with perfect hemostatic equilibrium with increase in both thrombocytic activity and equal increase in fibrinolytic activity.

Objective: To study the effect of exercise on blood pressure, heart rate, respiratory rate and other physiological blood parameters in healthy adults.

Materials and Methods: The study was conducted on 50 medical students. All the volunteers were male students of same age group ranging from 20 to 25 years. The subjects were made to exercise for 30 minutes and the following observations were recorded.

Results: The mean age, height, weight and body surface area of the subject were $22 \pm 2$ years, $171 \pm 11 \mathrm{cms}, 67 \pm 13 \mathrm{kgs}$ and $1.8 \pm 0.2$ respectively. The mean Heart rate before and after exercise was $77 \pm 3 \mathrm{bpm}$ and $174 \pm 9 \mathrm{bpm}$ respectively. The mean Respiratory rate was $17 \pm 1.0 \mathrm{bpm}$ and $25 \pm 2.5 \mathrm{bpm}$ respectively. The mean Systolic blood was $114 \pm 7.0 \mathrm{mmHg}$ and $146 \pm$ $6.0 \mathrm{mmHg}$ respectively. The mean Bleeding time was $1.70 \pm 0.4 \mathrm{~min}$ and $1.50 \pm 0.4 \mathrm{~min}$ respectively. The mean Clotting time was $3.50 \pm 0.6 \mathrm{~min}$ and $3.20 \pm 0.67 \mathrm{~min}$ respectively. The mean Platelet count was $3.50 \pm 0.6$ and $3.20 \pm 0.67$ respectively. The mean WBC count was $7934 \pm 772$ and $8403 \pm 693$ respectively.

Conclusion: All forms of exercise produce small benefits in controlling the blood pressure. The effects are similar to those of dietary and medication.

Keywords: Hypertension; Hemostatic Equilibrium; Thrombocytic; Fibrinolytic and Cardiovascular Diseases.

\section{Introduction}

The term exercise is used to denote physical activity that is planned structured, repetitive and purposeful. The main objective of physical exercise is improvement in or maintenance of one or more components of physical fitness.

Physiology of exercise has become an increasingly important topic for research and discussion. It has gained lot of importance as well as publicity by the work of pioneers in cardiovascular rehabilitation centers, who have demonsstrated the beneficial effects of exercise in cardiac and other patients in their recovery from disease and also in individuals with potential threat or susceptibility to disease, which have the roots as due to lack of physical activity. Exercise today has a scientific legitimacy due to research in physical education, exercise physiology and medicine.

Physical activity interventions have lowered systolic and diastolic blood pressure in hypertensive Adults [1], and may be effective in adolescents [2-4]. Considering that blood pressure levels in adolescence may "track" into adulthood, this possibility should be evaluated [2]. Mild exercises if repeated with an exercise prescription has an antihypertensive effects of $10-15 \mathrm{mmHg}$ in systolic pressure. The mechanism of reduction in blood pressure remains to be elucidated, although a correlation was shown with

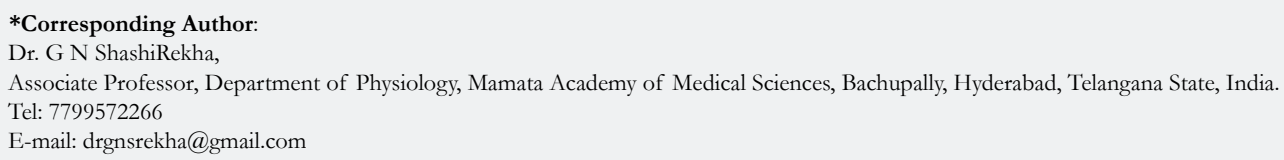

Citation: GN Shashi Rekha, Supriya Garapati, Asra Anjum. Study On Effect Of Exercise On Blood Pressure, Heart Rate, Respiratory Rate And Physiological Blood Parameters. Int J Anat Appl Physiol. 2020;6(2):135-143. doi: http://dx.doi.org/10.19070/2572-7451-2000025

Copyright: GN Shashi Rekha ${ }^{\circ} 2020$. This is an open-access article distributed under the terms of the Creative Commons Attribution License, which permits unrestricted use, distribution and reproduction in any medium, provided the original author and source are credited. 
sodium depletion and reduction of blood volume, it is possible that sweating may have depleted sodium reserves over the long period of exercise therapy. Due to this reason exercise is well worth considering as an adjunct to salt restriction and diuretics in uncomplicated mild hypertension.

Caspersen et al., (1985) defined physical activity in terms of the following three elements:

1. Movement of the body produced by skeletal muscles.

2. Resulting energy expenditure that varies from low to high.

3. A positive correlation with physical fitness.

Caspersen et al., (1985) attempted to distinguish between physical activity and exercise by considering possible sub-components of "activity". They defined exercise as: 1. Body movement produced by skeletal muscles. 2. Resulting energy expenditure varying from low to high. 3. Very positively correlated with physical fitness. 4. Planned, structured, and repetitive bodily movement. 5 . The objective is to maintain or improve physical fitness [5].

As far as health outcomes are concerned, the intensity, frequency, and duration of exercise have to be such that metabolic energy expenditure is usually well above that experienced at rest [6]. Moreover, recent work has demonstrated that standing and hence the recruitment of large muscle groups in the trunk and legs can make a contribution to health-related benefits [7].

Edward M. et al., in his study gave the following definitions and terms are intended to uphold principles of science and adhere to the SI: Function of muscle: the function of muscle is to exert force and it does so by attempting to shorten. Exercise: a potential disruption to homeostasis by muscle activity that is either exclusively, or in combination, concentric, eccentric or isometric. Intensity of exercise: this expression should be used instead of workload or work rate to indicate physiological, psychological or biomechanical demand on the participant by the performance of exercise [8].

It seems generally agreed that the acute reaction to exercise is an increased clotting tendency of blood. The increase of platelet count arises as a result of mobilization from deposits in peripheral vascular pool as catcholamines are secreted. Together with an increase of platelet stickiness it is one factor in the altered clotting tendency which undoubtedly contributes to the increased risk of heart attack during and immediately following exercise in old people and in persons with C.A.D. from the view point of preventive medicine it is important to emphasize that while the acute reaction to exercise is an increased clotting tendency the long term response is a decrease in the likelihood of intravascular coagulation, due to a balanced increase in clotting tendency and fibrinolytic activity [9]. In younger persons, hypertension often results from a higher cardiac output state, whereas in older persons, hypertension more often results from increased peripheral vascular resistance [10] and large artery stiffening [11]. Because of age-related differences in the cause of hypertension, it is not certain whether current exercise guidelines for hypertension fully apply to older persons [12].

\section{Materials and Methods}

The study was conducted on 50 medical students. All the volunteers were male students of same age group ranging from 20 to 25 years, they were carefully screened for any significant deviation of health from the normal basal findings. The subjects were made to exercise for 30 minutes and the following observations were recorded.

Collection of Anthropometric data:
a) Age
b) Height
c) Weight
d) Body Surface Area

Determination of Physiological parameters:
a) Heart rate
b) Blood pressure
c) Respiratory rate
d) Bleeding time
e) Clotting time
f) Leucocyte count
g) Platelet count

\section{Measuring the height}

The subject was asked to stand on a flat surface and take of his shoes, head bands or anything else from the head that may get in the way of an accurate measurement. The subject was asked to stand against a wall making sure his head, shoulders and buttocks are touching the wall. Line of sight and chin should be parallel to the floor. Using a wall mounted metallic tape measure, the height of the subject is measured.

\section{Measuring the weight}

Digital weighing balance was used to measure the weight of the students. Before starting the measurement the scale was adjusted to zero. The students were asked to take off heavy clothings (such as coats, jackets \pm and vests), purses, shoes and heavy accessories such as belts with heavy belt buckles. They should also remove everything from their pockets including money (coins), pens, pencils, wallets, and papers. Each student was asked to step on the scale and stand motionless in the middle of the scale platform with the feet slightly apart and the body weight distributed equally on both feet. Arms should be relaxed and hanging down loosely at the sides of the body. Digital scales are very sensitive to movement and any movement will change the weight measurement, so students must stand very still and the readings were recorded.

\section{Measuring the Body Surface Area}

Body Surface Area (BSA) measures the total surface area of the body. The Mosteller formula is most commonly used formula in practice and in clinical trials. The Mosteller formula takes the square root of the height $(\mathrm{cm})$ multiplied by the weight $(\mathrm{kg}) \mathrm{di}-$ vided by 3600 . 
BSA $\left(\mathrm{m}^{2}\right)=\sqrt{ }($ Height $(\mathrm{cm}) \mathrm{X}$ weight $(\mathrm{kg}) / 3600)$

\section{Motorized Treadmill}

All the subjects were made to walk on the treadmill for 30 minutes and physiological parameters were recorded. The treadmill is VENKY make athletic GIH model. The treadmill has a motordriven endless corrugated hard rubber track $450 \mathrm{~mm}$ wide that can be operated at any speed upto $12 \mathrm{kmph}$. It is possible to adjust the speed to easy mode, so that an ordinary individual can walk for hours and it can also be adjusted to high speed mode, so that the best runners can be exhausted in a very short time.

\section{Heart rate}

Method used to study heart rate is auscultation method. The auscultation is done with stethoscope in sitting position. The area auscultated is Mitral Valve.

\section{Blood pressure}

Method used is Auscultation method. The subject is asked to sit comfortably. The arm cuff is tied, brachial artery is palpated in the cubital fossa and the diaphragm of the stethoscope is kept on the brachial artery. Pressure is increased on the air pump till mercury level rises above the reading obtained by the palpatory method. Pressure is released very gradually till the banging sound is heard. The point represents the systolic pressure.

The pressure is being gradually released following the puffing noise there occurs a knocking or tapping sound which increases in intensity and then passes suddenly into another softer blowing sound. The sharp transition of krotokoff sounds from the loud banging to the soft blowing sound is taken as the diastolic pressure. Since the sharp transition cannot be possibly recorded correctly, hence cessation of sound may be taken as the reading for diastolic pressure.

\section{Respiratory Rate}

It is studied by inspection of the respiratory movements of the chest and abdomen. One inspiration and expiration make up one cycle.

\section{Stethography}

Tie a Stethography around the subject's chest at the level where the movements are maximum and have him sits with his back to the apparatus, asking the subject to relax and breathe naturally. Connect the Stethography to the tambour and adjust it so that excursions of the lever are satisfactory. Set kymograph at low speed $(1.2 \mathrm{~mm} /$ second) and record few respiratory movements. Note that the chest expands during inspiration, the stethograph gets stretched. The pressure within it decreases, and the atmospheric pressure pushes the diaphragm along with its writing lever of the tambour downwards. Thus down stroke is tracing in inspiration and the upstroke is expiration. Record a few normal cycles, and also after exercise.

\section{Bleeding time}

Method used is Duke's bleeding time. Get a finger prick (3-4mm) and note the time. The blood should flow freely without squeezing. Remove the blood drop every 30 seconds by absorbing them along the edge of a clean filter paper without pressing on the puncture and number them 1 onwards. Note the time when bleeding has stopped, that is when there is no trace of blood spots on the paper. Note that the successive spots are smaller, till there is no blood spot. Count the number of spots on the filter paper and express the result in minutes and seconds. Normal bleeding time is $1-5$ minutes.

\section{Clotting time}

Method used is capillary blood coagulation time. Get a deep finger prick and allow the blood to flow freely without squeezing.

Discard the first 2-3 drops and allow a large drop to form. Fill a capillary tube with blood by dipping one of its open ends in the drop. The blood rises and fills the tube by capillary action. Note the time. Break off $1 \mathrm{~cm}$ bits of the tube from one end every 30 seconds, and look for the formation of fibrin threads between the broken ends. The end-point is reached when fibrin threads span a gap of $5 \mathrm{~mm}$ between the broken ends. Note the time. Normal coagulation time is 3-6 minutes.

\section{White blood Cell Count}

Procedure: The finger is cleaned with spirit, pricked with a sterile needle. Clean and dried WBC pipette is taken and blood sucked up to 0.5 mark. Immediately diluting fluid is sucked up to 11 marks. The pipette is held between the thumb and the fore finger, in horizontal position mixing of blood and diluting fluid is done. The Neubaur's chamber is charged with the dilutant. The counting is done for WBC.

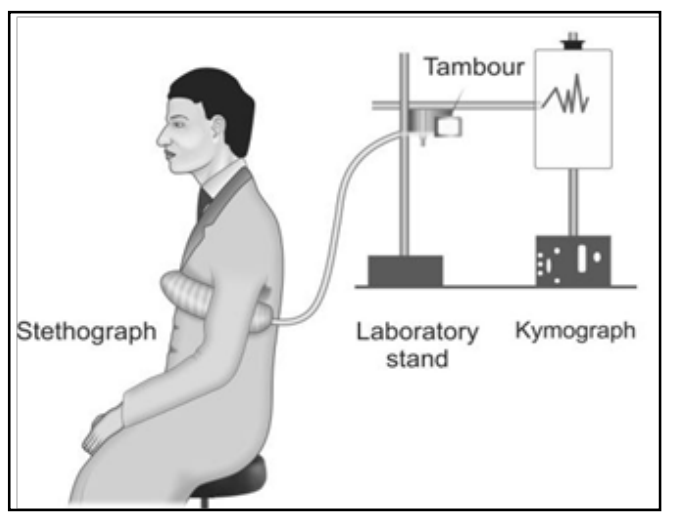




\section{Platelet count}

Fresh blood is diluted in a RBC pipette with Rees-Ecker fluid, and the stained platelets are then counted in a hemocytometer.

Composition:

Brilliant Cresyl Blue -0.05 gm

Sodium citrate $-3.80 \mathrm{gm}$

Formaldehyde $-0.2 \mathrm{ml}$ ( $40 \%$ formaldehyde solution)

Distilled water - $100 \mathrm{ml}$

Brilliant Cresyl Blue used for staining the platelets. Formaldehyde prevents the fungal growth. Sodium Citrate prevents the clotting of blood.

Freshly - filtered platelet solution id drawn to the mark of 0.5 in the RBC pipette.

Finger prick is given and blood is drawn into the pipette so that solution reaches the 1.0 mark. Reese-Ecker is taken in the pipette with blood upto the mark of 101. Mix the contents of the bulb for 2 minutes (this gives a dilution of 1 in 200). The purpose of taking 0.5 volume of platelets which occurs if blood is first taken into the pipette.

The first 2 drops are discarded and charge the counting chamber in the usual manner and platelet count is done in group of 5 in 16 squares each and calculated the number in $1 \mathrm{~mm}^{3}$ of undiluted blood.

\section{Results}

The study was conducted on 50 medical students. All the volunteers were male students of same age group ranging from 20 to 25 years. The mean age and Standard deviation of the students is $22 \pm 2$ years and standard error of mean is 0.3 . The lower limit of the confidence interval (95\%) is 21 years and upper limit is 23 years (table 1 and graph 1$)$.

The mean height is $171 \pm 11$ years with standard error of mean 1.7. The lower limit of the confidence interval (95\%) is $167 \mathrm{cms}$ and upper limit is $174 \mathrm{cms}$ (Table 1 and Graph 1).

The mean weight of the students is $67 \pm 13 \mathrm{kgs}$ with standard error of 20. The lower limit of confidence interval (95\%) is $62 \mathrm{kgs}$ and upper limit is $71 \mathrm{kgs}$ (Table 1 and Graph 1).
The mean Body Surface Area (BSA) is $1.80 \pm 0.2 \mathrm{~m}^{2}$ with standard error of mean 0.03 . The lower limit of confidence interval is $1.74 \mathrm{~m}^{2}$ and upper limit is $1.86 \mathrm{~m}^{2}$ (Table 1 and Graph 1).

The mean Heart rate before and after exercise are $77 \pm 3 \mathrm{bpm}$ and $174 \pm 9 \mathrm{bpm}$ respectively with standard error of mean 0.5 and 1.5 respectively. The lower limit of confidence interval is 76 and 172 bpm respectively and upper limit is 78 and $178 \mathrm{bpm}$ respectively. T-Value is 58.38 and $\mathrm{P}$ value $<0.0001$, which is highly significant (Table 2 and Graph 2).

The mean Respiratory rate before and after exercise are $17 \pm 1.0$ bpm and $25 \pm 2.5 \mathrm{bpm}$ respectively with standard error of mean 0.2 and 0.4 respectively. The lower limit of confidence interval is 16 and $24 \mathrm{bpm}$ respectively and upper limit is 17 and $26 \mathrm{bpm}$ respectively. T-Value is 20.97 and $\mathrm{P}$ value $<0.0001$, which is highly significant (Table 3 and Graph 3).

The mean Systolic blood pressure before and after exercise are $114 \pm 7.0 \mathrm{mmHg}$ and $146 \pm 6.0 \mathrm{mmHg}$ respectively with standard error of mean 1.0 and 1.0 respectively. The lower limit of confidence interval is 111 and $144 \mathrm{mmHg}$ respectively and upper limit is 115 and $148 \mathrm{mmHg}$ respectively. T-Value is 25.58 and $\mathrm{P}$ value $<$ 0.0001 , which is highly significant (Table 4 and Graph 4).

The mean Bleeding time before and after exercise are $1.70 \pm 0.4$ min and $1.50 \pm 0.4$ min respectively with standard error of mean 0.06 and 0.1 respectively. The lower limit of confidence interval is 1.50 and 1.38 min respectively and upper limit is 1.80 and 1.63 min respectively. T-Value is 3.19 and $\mathrm{P}$ value $<0.0003$, which is highly significant (Table 5 and Graph 5).

The mean Clotting time before and after exercise are $3.50 \pm 0.6$ min and $3.20 \pm 0.67$ min respectively with standard error of mean 0.09 and 0.10 respectively. The lower limit of confidence interval is 3.30 and $2.89 \mathrm{~min}$ respectively and upper limit is 3.70 and 3.32 min respectively. T-Value is 4.82 and $\mathrm{P}$ value $<0.0001$, which is highly significant (Table 6 and Graph 6).

The mean Platelet count before and after exercise are $3.50 \pm 0.6$ and $3.20 \pm 0.67$ respectively with standard error of mean 0.09 and 0.10 respectively. The lower limit of confidence interval is 3.30 and 2.89 respectively and upper limit is 3.70 and 3.32 respectively. T-Value is 19.02 and $P$ value $<0.0001$, which is highly significant (Table 7 and Graph 7).

The mean WBC count before and after exercise are $7934 \pm 772$ and $8403 \pm 693$ respectively with standard error of mean 122

Table 1. Demographic Data.

\begin{tabular}{|c|c|c|c|c|c|}
\hline \multirow{2}{*}{ Parameters } & \multirow{2}{*}{ Mean } & \multirow{2}{*}{ SD \pm} & \multirow{2}{*}{ SE \pm} & \multicolumn{2}{|c|}{$\begin{array}{c}\text { Confidence Inter- } \\
\text { val (95\%) }\end{array}$} \\
\cline { 5 - 6 } & & & & LL & UL \\
\hline Age (years) & 22 & 2 & 0.3 & 21 & 23 \\
\hline Height (cms) & 171 & 11 & 1.7 & 167 & 174 \\
\hline Weight (kgs) & 67 & 13 & 20 & 62 & 71 \\
\hline BSA $\left(\mathrm{m}^{2}\right)$ & 1.8 & 0.2 & 0.03 & 1.74 & 1.86 \\
\hline
\end{tabular}


Graph 1. showing Demographic Date.

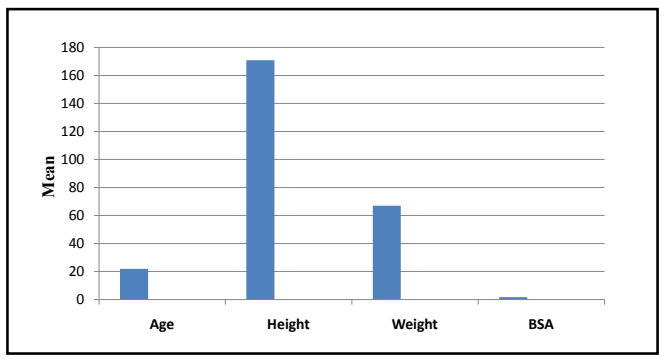

Table 2. Change in Heart Rate before and after exercise.

\begin{tabular}{|c|c|c|c|c|c|}
\hline \multirow{2}{*}{ Parameters } & \multirow{2}{*}{ Mean } & \multirow{2}{*}{ SD \pm} & \multirow{2}{*}{ SE \pm} & \multicolumn{2}{|c|}{$\begin{array}{c}\text { Confidence } \\
\text { Interval (95\%) }\end{array}$} \\
\cline { 5 - 6 } & & & & LL & UL \\
\hline Before exercise & 77 & 3 & 0.5 & 76 & 78 \\
\hline After exercise & 174 & 9 & 1.5 & 172 & 178 \\
\hline
\end{tabular}

T value $=58.38$

P value $<0.0001$, highly significant

Graph 2. Showing Change in Heart Rate before and after exercise.

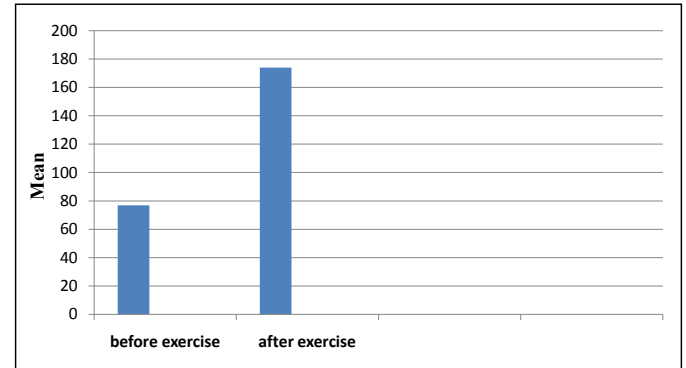

Table 3. Change in Respiratory Rate before and after exercise.

\begin{tabular}{|c|c|c|c|c|c|}
\hline \multirow{2}{*}{ Parameters } & \multirow{2}{*}{ Mean } & \multirow{2}{*}{ SD \pm} & \multirow{2}{*}{ SE \pm} & \multicolumn{2}{|c|}{ Confidence } \\
\cline { 4 - 6 } & & & & Lnterval (95\%) & UL \\
\hline Before exercise & 17 & 1 & 0.2 & 16 & 17 \\
\hline After exercise & 25 & 2.5 & 0.4 & 24 & 26 \\
\hline
\end{tabular}

$\mathrm{T}$ value $=20.97 ; \mathrm{P}$ value $<0.0001$, highly significant

Graph 3. Showing Change in Respiratory Rate before and after exercise.

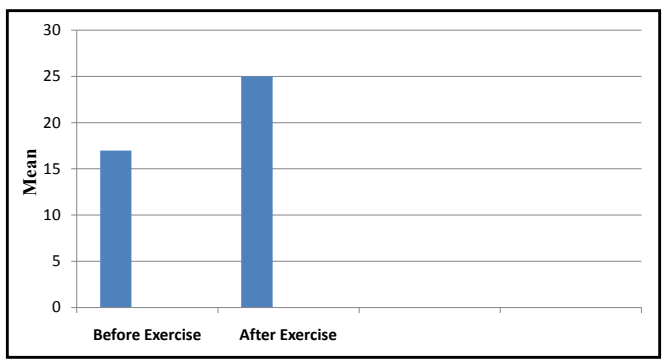

Table 4. Change in Systolic BP before and after exercise.

\begin{tabular}{|c|c|c|c|c|c|}
\hline \multirow{2}{*}{ Parameters } & \multirow{2}{*}{ Mean } & \multirow{2}{*}{ SD \pm} & \multirow{2}{*}{ SE \pm} & \multicolumn{2}{|c|}{$\begin{array}{c}\text { Confidence } \\
\text { Interval (95\%) }\end{array}$} \\
\cline { 5 - 6 } & & & & LL & UL \\
\hline Before exercise & 114 & 7 & 1 & 111 & 115 \\
\hline After exercise & 146 & 6 & 1 & 144 & 148 \\
\hline
\end{tabular}

$\mathrm{T}$ value $=25.58 ; \mathrm{P}$ value $<0.0001$, highly significant 
Graph 4. Change in Systolic BP before and after exercise.

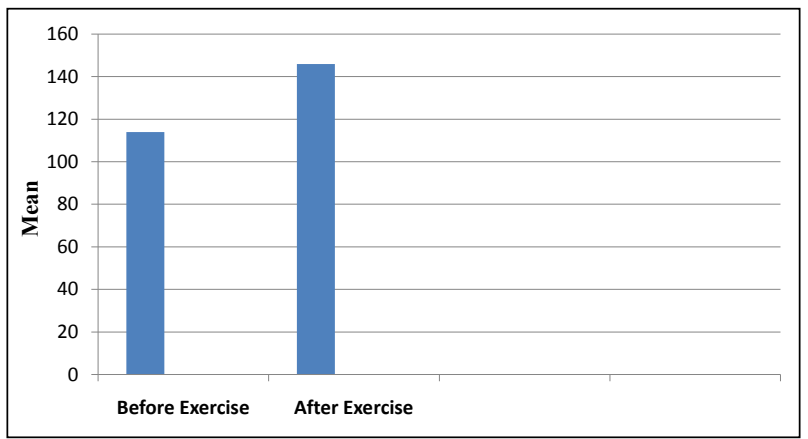

Table 5. Changes in Bleeding time before and after exercise.

\begin{tabular}{|c|c|c|c|c|c|}
\hline \multirow{2}{*}{ Parameters } & \multirow[t]{2}{*}{ Mean } & \multirow[t]{2}{*}{$\mathrm{SD} \pm$} & \multirow[t]{2}{*}{ SE \pm} & \multicolumn{2}{|c|}{$\begin{array}{c}\text { Confidence } \\
\text { Interval (95\%) }\end{array}$} \\
\hline & & & & LL & $\mathrm{UL}$ \\
\hline Before exercise & 1.7 & 0.4 & 0.06 & 1.5 & 1.8 \\
\hline After exercise & 1.5 & 0.4 & 0.1 & 1.38 & 1.63 \\
\hline
\end{tabular}

$\mathrm{T}$ value $=3.19 ; \mathrm{P}$ value $<0.003$, highly significant

Graph 5. Changes in Bleeding time before and after exercise.

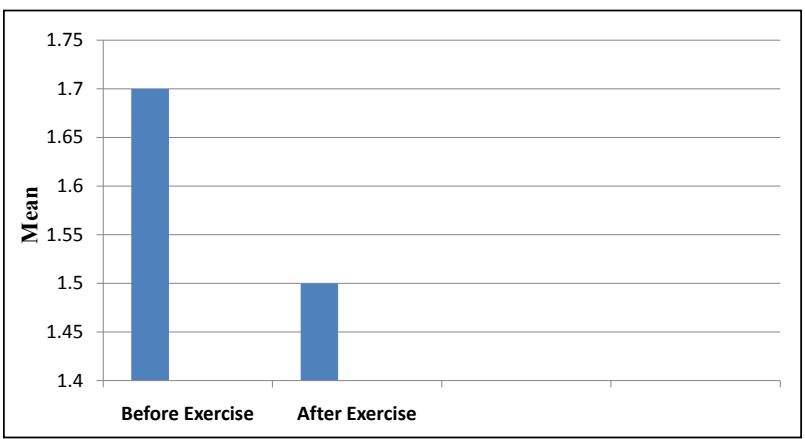

Table 6. Changes in Clotting time before and after exercise.

\begin{tabular}{|c|c|c|c|c|c|}
\hline \multirow{2}{*}{ Parameters } & \multirow{2}{*}{ Mean } & \multirow{2}{*}{ SD \pm} & \multirow{2}{*}{ SE \pm} & \multicolumn{2}{|c|}{$\begin{array}{c}\text { Confidence Inter- } \\
\text { val (95\%) }\end{array}$} \\
\cline { 5 - 6 } & & & & LL & UL \\
\hline Before exercise & 3.5 & 0.6 & 0.09 & 3.3 & 3.7 \\
\hline After exercise & 3.2 & 0.67 & 0.1 & 2.89 & 3.32 \\
\hline
\end{tabular}

$\mathrm{T}$ value $=4.82 ; \mathrm{P}$ value $<0.0001$, highly significant

Graph 6. Changes in Clotting time before and after exercise.

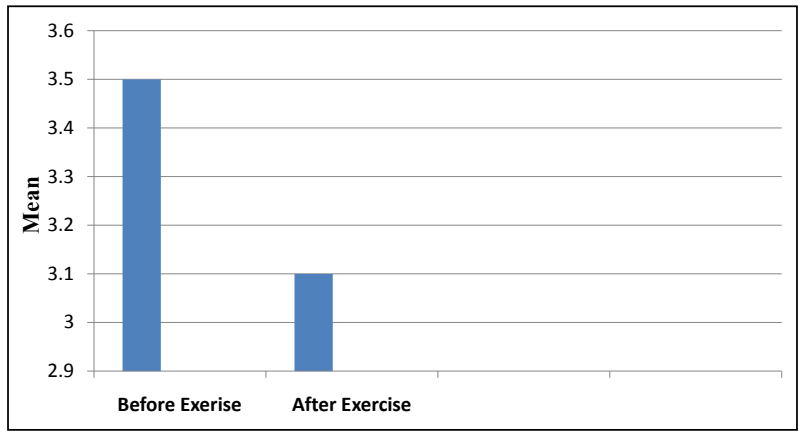


Table 7. Changes in Platelet Count in lakhs before and after exercise.

\begin{tabular}{|c|c|c|c|c|c|}
\hline \multirow{2}{*}{ Parameters } & \multirow{2}{*}{ Mean } & \multirow{2}{*}{ SD \pm} & \multirow{2}{*}{ SE \pm} & \multicolumn{2}{|c|}{$\begin{array}{c}\text { Confidence } \\
\text { Interval (95\%) }\end{array}$} \\
\cline { 5 - 6 } & & & & LL & UL \\
\hline Before exercise & 3.5 & 0.6 & 0.09 & 3.3 & 3.7 \\
\hline After exercise & 3.2 & 0.67 & 0.1 & 2.89 & 3.32 \\
\hline
\end{tabular}

$\mathrm{T}$ value $=19.02 ; \mathrm{P}$ value $<0.0001$, highly significant.

Graph 7. Showing Changes in Platelet Count in lakhs before and after exercise.

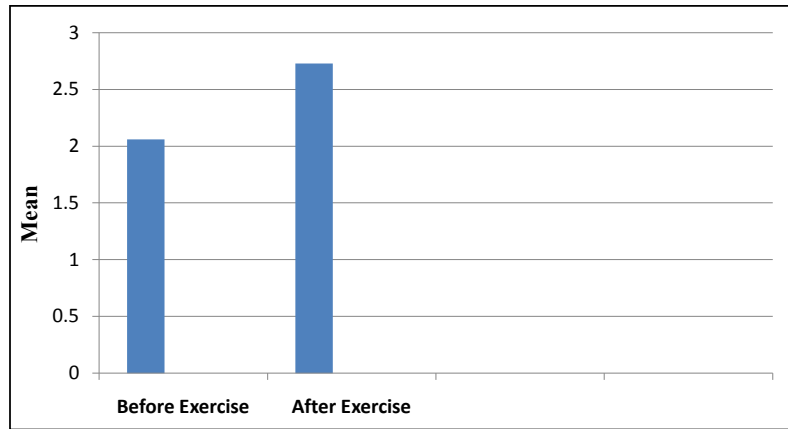

Table 8. Changes in WBC Count before and after exercise.

\begin{tabular}{|c|c|c|c|c|c|}
\hline \multirow{2}{*}{ Parameters } & \multirow{2}{*}{ Mean } & SD \pm & \multirow{2}{*}{ SE \pm} & \multicolumn{2}{|c|}{$\begin{array}{c}\text { Confidence } \\
\text { Interval (95\%) }\end{array}$} \\
\cline { 5 - 6 } & & & & LL & UL \\
\hline Before exercise & 7934 & 772 & 122 & 7687 & 8181 \\
\hline After exercise & 8403 & 693 & 110 & 8181 & 8625 \\
\hline
\end{tabular}

T value $=8.07 ; \mathrm{P}$ value $<0.0001$, highly significant

Graph 8. Showing Changes in WBC Count before and after exercise.

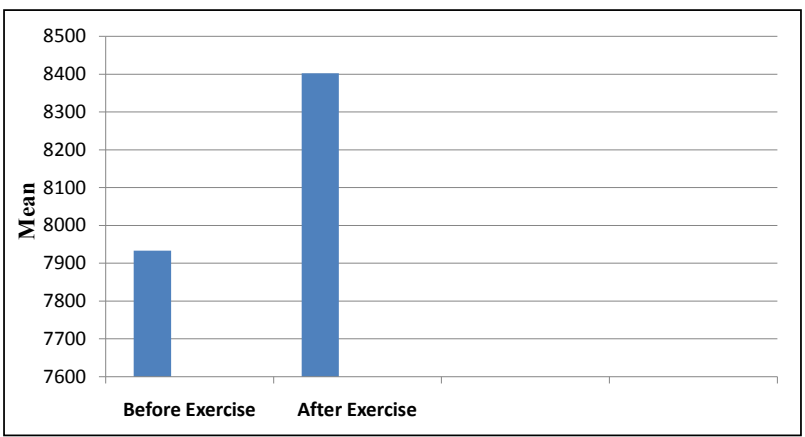

and 110 respectively. The lower limit of confidence interval is 7687 and 8181 respectively and upper limit is 8181 and 8625 respectively. T-Value is 8.07 and $\mathrm{P}$ value $<0.0001$, which is highly significant (Table 8 and Graph 8 ).

\section{Discussion}

The aim of studying the effects of exercise on hemostasis in healthy subjects has its reason. In previous studies which have shown above $25 \%$ of all cases of new myocardial infarction and $14 \%$ of all cases of sudden cardiac deaths are caused by sporadic increased physical activity. Because in recent years many patients recovering from myocardial infarcts have been treated with exercise therapy.
The primary concern of the physician must always be to prevent disease as well as to treat the person suffering from it in whatever form it may occur. The effective prevention and treatment depends on understanding the causes of these disorders, and understanding the harmful factors, the scope of modern medical research and medical investigation has widened to include all the scientific disciplines.

The great contributions made towards the improvement of health and conquest of disease by science. The great physicians have always demonstrated a broad interest in human anatomy and physiology. They have been extremely conscious of the effects of man's activity on his state of health. Even before scientific bases had been established upon which sound recommendations could be made, their observations led many of them to advise 
empirically that health could better be maintained and restored by exercise rather than rest.

\section{Changes seen in Heart Rate}

The heart rate was significantly increased during exercise from mean value of $77 / \mathrm{min}$ to $174 / \mathrm{min}$ with $\mathrm{T}$ value of 58.38 and $\mathrm{P} \leq$ 0.0001 , which is highly significant. In the study done by Deuk - Ja Oh et al., they found the Heart rate before and after exercise as $58.80 \pm 4.38$ and $169.67 \pm 12.83$ respectively.

There occurred sudden increase in heart rate with the start of performance and this gets stabilized at a slightly lower level of increase as the exercise continued. The initial sudden increase in heart rate at the onset of exercise is attributed to "anticipatory" response produced by cerebral cortex, with continuation of exercise apprehension for the exercise is lost and sustained rise of the heart rate persist. After termination of exercise within 5 to $6 \mathrm{~min}$ the heart rate comes to pre-exercise basal level [13].

\section{Changes seen in blood pressure}

The mean Systolic blood pressure was significantly raised after exercise from $114 \mathrm{mmHg}$ to $146 \mathrm{mmHg}$ with T value of 25.58 and $\mathrm{P} \leq 0.0001$. Rashida Bhatti et al., found the mean systolic blood pressure was $118.64 \pm 8.05 \mathrm{mmHg}$ and $139.32 \pm 12.5 \mathrm{mmHg}$ before and after exercise respectively and the mean diastolic blood pressure was $77.59 \pm 7.19 \mathrm{mmHg}$ and $110.91 \pm 14.79 \mathrm{mmHg}$ before and after exercise respectively [14]. In another study done by Deuk-Ja Oh et al., the mean systolic blood pressure was 124.67 $\pm 7.83 \mathrm{mmHg}$ and $219.53 \pm 29.31 \mathrm{mmHg}$ before and after strenuous exercise respectively and the mean diastolic blood pressure was $79.53 \pm 2.80 \mathrm{mmHg}$ and $78.60 \pm 10.64 \mathrm{mmHg}$ before and after strenuous exercise $[13,14]$.

This increased systolic blood pressure is seen in all types of exercises, mild moderate and early stages of strenuous exercises. It has been assumed that with onset of exercise their occurred profound vasodilatation in exercising muscle. This will tend to produce an initial fall of systolic Bp and these initial falls activate baroreceptors control system which elevates the blood pressure. A stronger effect on rise of blood pressure is exerted by increased sympathetic nervous system activity which causes instant release of catecholamine, which keeps the blood pressure higher throughout the performance of physical activity. This response of blood pressure rise is not upto a maximal level in case of unfit persons, a physically unfit person will not show rise of blood pressure instead his blood pressure will fall. With regard to diastolic blood pressure there occurs no change in values by light and moderate exercise, heavy exercise may cause slight increase in diastolic pressure.

According to Chobanian et al., (2003), it is reported that, as a positive effect of exercises, hypotensive effect due to exercises is about 4-9 $\mathrm{mmHg}$ [15]. The mechanism in which exercises have effect on blood pressure is different depending on exercise intensity, time, and exercise types, but it is known that blood pressure is decreased due to decreased activity of sympathetic nervous system and decreased peripheral resistance [16]. This exerciseinduced high blood pressure has 5-10 times higher rates to shift to high blood pressure in a future stability [17], and it is also an independent risk factor for cardiovascular and cerebro-vascular diseases $[18,19]$.

\section{Changes seen in Respiratory rate}

The respiratory rate was significantly increased from mean values of $17 / \mathrm{min}$ to $25 / \mathrm{min}$ during exercise with $\mathrm{T}$ value of 20.97 and $\mathrm{P} \leq 0.0001$. This increased respiratory rate is increased by many folds increased in alveolar $\mathrm{Pco}_{2}$ from basal $40 \mathrm{mmHg}$ to 43 $\mathrm{mmHg}$ during the exercise this illustrate the role of respiration in supplying the extra demand of oxygen during the exercise.

\section{Changes seen in Blood parameters}

The change in bleeding time was significant in the present study. The mean values before and after exercise was 1.70 to $1.50 / \mathrm{min}$ with T value of 3.19 and $P$ value $\leq 0.003$ was significantly reduced.

The change in clotting time was significant in the present study. The mean values before and after exercise were 3.50 to $3.10 /$ min with $\mathrm{T}$ value of 4.82 and $\mathrm{P}$ value $\leq 0.0001$ was significantly reduced.

The change seen in platelet count was also significantly increased from mean value of 2.06 to 2.73 lakhs after exercise with $T$ value of 19.02 and $P$ value $\leq 0.0001$.

With regard to above changes in hemostatic mechanisms during the exercise the insight to this is originated from the observation that sudden deaths are reported in immediate post exertion period by all probability such deaths occur due to thrombo-occlusive disease. The constituents of body which can cause increase in tendency for thrombosis includes- a) rise in viscosity of blood, b) decrease in velocity of blood flow. Leading to some degree of stasis of blood associated with this there occur activity of inert clotting factors which produces enhance rate of blood coagulation and shortening of bleeding time and clotting time.

Hemostasis is also jeopardized by such physical mechanism which causes mobilization platelets from platelet depots and increase circulating platelet increases the tendency to blood clotting. It is to note that hemostatic equilibrium which operates on one side with increase thrombocytic activity, on other side with fibrinolytic activity gets altered in patients with occlusion of coronary artery. Whereas in normal individual there exists a perfect hemostatic equilibrium with increase in both thrombocytic activity and equal increase in fibrinolytic activity. That in normal individual a moderate exercise does not predispose to intravascular coagulation.

A change seen in WBC count was significantly increased with mean value of 7934 to 8403 with T value of 8.07 and $P$ value of $<0.0001$ was significant. During exercise it is seen that there occur an increase in circulating number of WBC. The mechanism for increase in peripheral circulating WBC is due to mobilization of white blood cells from marginal pools to circulating pool. It is to note that several studies have demonstrated in prolonged exercise. To examine the effect of exercise training on white blood cell count response to exercise, both trained and untrained healthy male subjects were made to exercise in the study conducted by M. Gimenez et al., Both trained and untrained subjects were made to exercise for 15 minutes and the results showed that both groups differ in maximal work load and total exercise, but increase in total WBC count lymphocytes and platelet count has occurred 
in both the trained as well as untrained groups. There appears to be no difference between untrained and trained subjects in the increase of WBC and platelet count. The total platelet count were higher in trained subjects both at rest and after exercise. This appears related to the higher level of exercise performed by trained subjects. Inference given that exercise increases the platelet count, the higher resting values observed in trained subjects may reflect a persistent response to previous bouts of exercise [20].

Galun E et al., at Tel Air University Israel have conducted the study of response of leucocytosis in straneous physical exercise. e.g. a 2 hours $(120 \mathrm{~km})$ march shows initial increase in total WBC count for first $16 \mathrm{hrs}$ of march say from $8,500 / \mathrm{cmm}$ to $11,500 / \mathrm{cmm}$ and then declined to $7,100 / \mathrm{cmm}$ by the end of 24 hrs march. In this strenuous exercise there also occurred a rise in plasma creation phosphatase activity indicating the occurrence of muscle damage. The subsequent fall in total WBC count indicates that WBC has migrated from circulating pool to damaged muscle [21].

Rashida Bhatti in her study stated that the WBC count is $6419 \pm$ $1186 / \mathrm{mm}^{3}$ and $12478.6 \pm 2915.53 / \mathrm{mm}^{3}$ before and after exercise respectively [14].

\section{Summary}

A study was undertaken to determine whether physical activity and training increases the risk of thrombo-embolism. The study showed that there occurs a slight increase in thrombocytic activity, simultaneously with a beneficial increase in fibrinolytic activity.

\section{Acknoldegements}

I most humbly acknowledge the students who co-operated me to take the data for the article and the statistician. I also acknowledge the authors, editors and publishers of all those articles, journals and books from where the literature for this article has been reviewed and discussed.

\section{Conclusion}

The results obtained from the study can be applied for betterment of individual's health by creating better basal health and also superimposed better performance during subsequent physical exercise. Tailored, programmed and prescribed exercise definitely will induce a good physiological response and this can be utilized for improving the functional capacity of each and every system of human body.

\section{References}

[1]. Andrade S, Lachat C, Ochoa-Aviles A, Verstraeten R, Huybregts L, Roberfroid, et al. A school-based intervention improves physical fitness in Ecuado- rian adolescents: a cluster-randomized controlled trial. International Journal of Behavioral Nutrition and Physical Activity. 2014; 11(1): 153. PMID: 25490946.

[2]. O'Donovan C, Greally P, Canny G, McNally P, Hussey J. Active video games as an exercise tool for children with cystic fibrosis. Journal of Cystic Fibrosis. 2014; 13(3): 341-346. PMID: 24189057.

[3]. Luísa Dias Quitério A. School physical education: The effectiveness of health-related interventions and recommendations for health-promotion practice. Health Education Journal. 2013; 72(6), 716-732.

[4]. Pradeep A. Praveen, Roy A, Prabhakaran D. Cardiovascular Disease Risk Factors: A Childhood Perspective. The Indian Journal of Pediatrics. 2013; 80(S1): 3-12. PMID: 22638996.

[5]. Caspersen CJ, Powell KE, Christenson GM. Physical activity, exercise and physical fitness: Definitions and distinctions for health-related research. Public Health Reports. 1985; 100: 126-131. PMID: 3920711.

[6]. Bouchard C, Shephard RJ. Physical Activity, Fitness, and Health: The Model and Key Concepts. In physical Activity, Fitness, and Health. International Proceedings and Consensus Statement Edited by: CB, RJ, and TS. Toronto: Human Kinetics. 1994.

[7]. Hamilton MT, Hamilton DG, Zderic TW. The role of low energy expenditure and sitting on obesity, metabolic syndrome, Type 2 diabetes and cardiovascular disease. Diabetes. 2007; 56: 2655-2667. PMID: 17827399.

[8]. Edward M. Winter, Fowler N. Exercise defined and quantified according to the Système International d'Unités, Journal of Sports Sciences. 2009; 27(5): 447-460. PMID: 19253082.

[9]. Cox MH, Shephard RJ, Corey P. Physical activity and alienation in the workplace. Journal of sports medicine and physical fitness. 1987; 27(4): 429-36.

[10]. Montain SJ, Jilka SM, Ehsani AA, Hagberg JM. Altered hemodynamics during exercise in older essential hypertensive subjects. Hypertension. 1988; 12: 479- 484.

[11]. Cheitlin MD. Cardiovascular physiology: changes with aging. Am J Geriatr Cardiol. 2003; 12: 9-13. PMID: 12502909.

[12]. Pescatello LS, Franklin BA, Fagard R, Farquhar WB, Kelley GA, Ray CA. American College of Sports Medicine position stand: exercise and hypertension. Med Sci Sports Exerc. 2004; 36: 533-553. PMID: 15076798.

[13]. Deuk-Ja Oh, Hyeon - Ok Hong, Bo - Ae Lee. The effect of strenuous exercise on resting heart rete, blood pressure and maximal oxygen uptake. J exerc Rehabil. 2006: 12(1): 42-46. PMID: 26933659.

[14]. Bhatti R, Muhammad Shaikh Bin. The effect of exercise on blood parameters. Pak J Physiol. 2007; 3(2).

[15]. Chobanian AV, Bakris GL, Black HR, Cushman WC, Green LA, Izzo JL, et al. National Heart, Lung, and Blood Institute Joint National Committee on Prevention, Detection, Evaluation, and Treatment of High Blood Pressure; National High Blood Pressure Education Program Coordinating Committee. The Seventh Report of the Joint National Committee on Prevention, Detection, Evaluation, and Treatment of High Blood Pressure: the JNC 7 report. JAMA. 2003; 289: 2560-2572.

[16]. Cavalcante MA, Bombig MT, Luna Filho B, Carvalho AC, Paola AA, Póvoa R. Quality of life of hypertensive patients treated at an outpatient clinic. Arq Bras Cardiol. 2007; 89: 245-250.

[17]. Singh JP, Larson MG, Manolio TA, O’Donnell CJ, Lauer M, Evans JC, et al. Blood pressure response during treadmill testing as a risk factor for newonset hypertension. The Framingham heart study. Circulation. 1999; 99: 1831-1836. PMID: 10199879.

[18]. Kurl S, Laukkanen JA, Rauramaa R, Lakka TA, Sivenius J, Salonen JT. Systolic blood pressure response to exercise stress test and risk of stroke. Stroke. 2001; 32: 2036-2041. PMID: 11546894.

[19]. Tzemos N, Lim PO, Mackenzie IS, MacDonald TM. Exaggerated exercise blood pressure response and future cardiovascular disease. J Clin Hypertens (Greenwich). 2015; 17: 837-844. PMID: 26235814.

[20]. Gimenez M, Mohan Kumar T, Humbert JC, de Talance N, Teboul M, Belenguer FJA. Training and leucocyte, lymphocyte and platelet response to dynamic exercise. Journal of sports medicine. 1987; 27: 172-177. PMID: 2821322.

[21]. Galun E, Burstein R, Assia E, Tur-Kaspa I, Rosenblum J, Epstein Y. Changes of white blood cell count during prolonged exercise. International Journal of Sports Medicine. 1987; 8(4): 253-255. 